\title{
Catch me if you can: how AML and its niche escape immunotherapy
}

\author{
Sarah Tettamanti ${ }^{1,3}$, Alice Pievani ${ }^{1,3}$, Andrea Biondi $\mathbb{D}^{1 \times}{ }^{凶}$, Gianpietro Dotti ${ }^{2,3}$ and Marta Serafini (DD ${ }^{1,3}$
}

(c) The Author(s) 2021

In spite of the remarkable progress in basic and preclinical studies of acute myeloid leukemia (AML), the five-year survival rate of AML patients remains poor, highlighting the urgent need for novel and synergistic therapies. Over the past decade, increased attention has been focused on identifying suitable immunotherapeutic strategies for AML, and in particular on targeting leukemic cells and their progenitors. However, recent studies have also underlined the important contribution of the leukemic microenvironment in facilitating tumor escape mechanisms leading to disease recurrence. Here, we describe the immunological features of the AML niche, with particular attention to the crosstalk between the AML blasts and the cellular components of the altered tumor microenvironment (TME) and the mechanisms of immune escape that hamper the therapeutic effects of the most advanced treatments. Considering the AML complexity, immunotherapy approaches may benefit from a rational combination of complementary strategies aimed at preventing escape mechanisms without increasing toxicity.

Leukemia (2022) 36:13-22; https://doi.org/10.1038/s41375-021-01350-x

\section{INTRODUCTION}

The concept of adoptive immunotherapy was described for the first time by Mathé in the late ' 60 s in the context of allogeneic hematopoietic stem cell transplantation (HSCT) for the treatment of acute myeloid leukemia (AML). The graft-vs-leukemia effect, by which leukemia can be eradicated by the immune cells from the donor graft, revolutionized the field of cancer therapy and has since evolved to targeted immunotherapeutic strategies such as chimeric antigen receptor (CAR) redirected T cells, bispecific T-cell engagers (BiTEs) and checkpoint inhibitors. Furthermore, it became evident that $A M L$ development and progression are associated with dysregulated immune responses. In particular, recent studies have highlighted how leukemic cells manipulate and alter the tumor microenvironment (TME) creating a unique niche that directly promotes their survival as well as drug resistance.

This review is aimed at describing the biological properties of the AML niche, the crosstalk between AML blasts, and cellular components of the TME, considering the non-hematopoietic participants such as stromal cells and vascular endothelium, and the development of resistance towards immunotherapeutic strategies. We will then review the most innovative concepts supporting therapeutic combinations that may overcome the current barriers in AML treatment.

\section{HOW AML AND ITS NICHE AFFECT IMMUNOTHERAPY}

\section{AML blast-induced resistance to immunotherapy}

There is compelling evidence that AML blasts play a role in the creation of weathered gears in the host immune system through several unique immune evasion mechanisms (Fig. 1). Tumor escape strategies in AML involve direct adaptation of the AML cells to hide from immune recognition and tumor-cell-mediated modifications of the immune cell compartment that include effector $\mathrm{T}$ cells, natural killer cells (NKs), and dendritic cells (DCs). With the advent of spatially-resolved immunohistochemistry, high-throughput single-cell transcriptomic, proteomic, and mass cytometry technologies it is possible to better decipher the AML immunologic microenvironment and to envision more tailored immunotherapeutic strategies for the future of AML treatment [1-5].

\section{AML are defective in antigen presentation}

The success of allogenic HSCT relies on the ability of T and NK cells to recognize and eliminate leukemic cells. AML blasts have developed immunoediting processes, such as genetic deletion of HLAs, especially in the context of the haploidentical transplant, and epigenetic downregulation of HLA class II molecules in different donor transplant settings, which preclude conventional recognition of $A M L$ blasts by CD8 and CD4 T cells via aßTCR engagement with peptides presented in class I and II. Gene

\footnotetext{
${ }^{1}$ Tettamanti Research Center, Department of Pediatrics, University of Milano-Bicocca/Fondazione MBBM, Monza, Italy. ${ }^{2}$ Lineberger Comprehensive Cancer Center, University of North Carolina at Chapel Hill, Chapel Hill, NC, USA. ${ }^{3}$ These authors contributed equally: Sarah Tettamanti, Alice Pievani, Gianpietro Dotti, Marta Serafini. ${ }^{\circledR}$ email: abiondi. unimib@gmail.com
}

Received: 6 May 2021 Revised: 9 July 2021 Accepted: 12 July 2021

Published online: 23 July 2021 


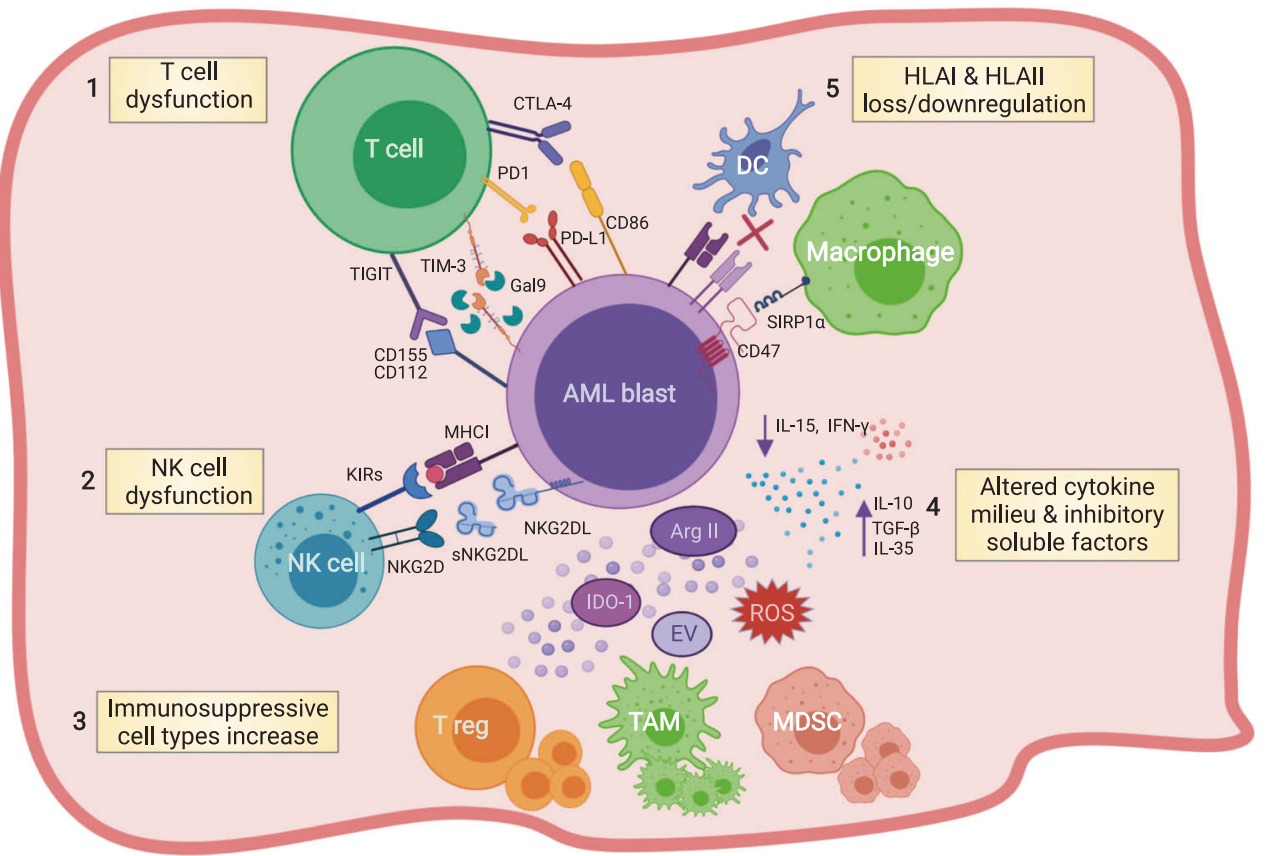

Fig. 1 AML blast's immune escaping strategies. Schematic illustration summarizing the most known immune evasion mechanisms exerted by AML blasts. AML blasts can hamper T- and NK-cell effector functions by aberrantly overexpressing inhibitory T-cell ligands (i.e. PD-L1, Gal-9, CD155, CD112, CD86) (1), or by releasing soluble forms of NKG2DL (2). AML blasts promote T-cell exhaustion and apoptosis, drive the expansion of regulatory T cells (Tregs) and myeloid-derived suppressor cells (MDSCs), and induce the switch of macrophages to tumorassociated macrophages (TAMs) (3) by altering the cytokine milieu and through the release within the BM niche of other soluble factors such as reactive oxygen species (ROS), indoleamine 2,3-dioxygenase-1 (IDO1), arginase II (Argll), and extracellular vesicles (EVs) (4). Moreover, AML blasts reduce their expression of antigen presentation molecules, thus hiding themselves from immune cells such as dendritic cells (DCs) and macrophages (5). Figure created with Biorender.

expression profiling of $A M L$ blasts from patients relapsed after HSCT has uncovered transcriptional signatures enriched in altered immune-related processes, including the epigenetic downregulation of HLA class II genes, the genomic loss of HLA, the epigenetic upregulation of $\mathrm{T}$ cells inhibitory ligands, and the deregulated release of immunosuppressive molecules [6-9].

\section{AML blasts express immune checkpoint markers}

Immune Checkpoints (ICs) are regulatory molecules expressed on $\mathrm{T}$ cells to activate self-tolerance and prevent autoimmunity. To evade immune surveillance, leukemic blasts aberrantly express the ligands for ICs [6]. The role of each co-inhibitory pathway in AML has been extensively described in a recent review by Taghiloo and Asgarian-Omran [10]. The most well-known AML ligand for a IC is programmed-cell-death ligand-1 (PD-L1) that, once recognized by the PD-1 receptor on $\mathrm{T}$ cells, provides a co-inhibitory signal that causes T-cell exhaustion. Moreover, the PD-1/PD-L1 axis can also promote the expansion of regulatory $T$ cells (Tregs), which further hampers the effector function of CD8 T cells. T-cell immunoglobulin and mucin domain 3 (TIM-3) is a well-defined IC in both effector T and NKcells. TIM-3 binds to galectin-9, which is highly expressed on AML blasts, and has been found to promote self-renewal via stimulatory $\beta$-catenin and NFKB-signaling, and to reduce the release of pro-inflammatory cytokines, ultimately resulting in NK- and T-cell dysfunction. Furthermore, galectin-9 is highly involved in creating an autocrine loop that seems essential in the maintenance of leukemic stem cells (LSCs) $[11,12]$. In AML murine models and in patients there is a strong association between high frequency of TIM-3 $3^{+}$and PD- $1^{+}$T cells and poor prognosis [13-16]. Another inhibitory receptor, TIGIT (T-cell immunoglobulin and ITIM domain), which binds to the same ligands as DNAM-1, CD155, and CD112, has also been shown to be upregulated in AML blasts. Interestingly, low levels of DNAM-1 expression are observed in AML patients, while its ligands are highly expressed $[17,18]$ suggesting that the binding of TIGIT with CD112 and CD155 ligands may represent a mechanism of tumor immune escape promoted by immune cell inhibitory signaling. This notion is further supported by clinical observations showing that CD112 and CD155 expression are associated with poor prognosis in AML [19]. In another recent study, high mRNA levels of the inhibitory receptors Cytotoxic Tlymphocyte associated protein 4 (CTLA4) and lymphocyte activating-3 (LAG-3) in AML blasts were also shown to be predictive of an unfavorable prognosis [20]. A peculiar checkpoint and AML LSC marker that plays a crucial role in immune evasion is CD47, a transmembrane protein that by binding to its receptor Signal Regulatory Protein Alpha (SIRPa) on macrophages exerts a "don't eat me" signal by blocking macrophage engulfment [21]. It is physiologically expressed by various types of normal cells but has emerged as a potent common signal by which cancer cells evade the innate immune system [22].

Immune Checkpoint Inhibitors (ICls) targeting PD-1/PD-L1 and CTLA4 are highly effective in patients with solid tumors characterized by high neoantigen loads such as melanoma and lung cancer, and have become standard of care for these patients. ICls are currently explored in multiple clinical trials of patients with hematologic malignancies including AML. Combinatorial approaches are also underway by exploiting other ICls, such as CD47, TIM-3, TIGIT, and LAG-3.

\section{AML blasts alter the formation of T-cell immune synapses}

One of the most comprehensive study that analyzed the T-cell compartment in AML was performed by Le Dieu et al. They observed that the absolute number of $T$ cells in the peripheral blood (PB) of newly diagnosed AML patients was increased compared with age-matched healthy controls. Furthermore, gene expression profiling revealed an aberrant T-cell activation signature 
in AML patients. In particular, differentially expressed genes were involved in actin cytoskeletal formation, and correlative functional data demonstrated an impaired capacity of $T$ cells in forming an immune synapse with AML blasts [23]. These results are in line with previous studies showing that $\mathrm{T}$ cells isolated from AML patients are phenotypically effector cytotoxic $T$ lymphocytes, express activation markers, but are impaired in their cytotoxic potential defined as the capacity to express cytotoxic granules [24].

\section{AML secrete immunoinhibitory soluble factors altering T-cell immune responses}

T-cell functional alterations in AML are also a consequence of a dysregulated cytokine network directly mediated by AML blasts. Several studies have documented high numbers of Tregs in patients with AML $[25,26]$. In particular, Shenghui et al. showed that elevated frequency of $\mathrm{CD} 4^{+} \mathrm{CD} 25^{+} \mathrm{CD} 127^{\text {low/- }}$ Tregs in $\mathrm{AML}$ is associated with poor prognosis. Moreover, it was observed that bone marrow (BM)-resident Tregs were more immunosuppressive than Tregs detected in PB further supporting the concept that the AML niche is characterized by multiple layers of inhibitory cells [27]. Tregs enrichment in the AML niche has been associated with the capacity of AML blasts to secret immunoinhibitory factors, such as IL-10, IL-35, transforming growth factor-beta (TGF- $\beta$ ), and indoleamine 2,3-dioxygenase 1 (IDO1) [28-30]. These soluble factors push T-cell polarization towards induced Tregs promoting T-cell tolerance and leukemia progression. IDO1 in particular has been shown to correlate with poor prognosis [31]. IDO1 catabolizes the degradation of tryptophan to $\mathrm{N}$-formylkynurenine. The reduction in local tryptophan concentration and accumulation of toxic tryptophan metabolites cooperate to arrest T-cell proliferation. Moreover, tryptophan-derived metabolites like L-kynurenine inhibit antigen-specific T-cell proliferation and induce T-cell apoptosis. This cytokine imbalance reduces the production of pro-inflammatory cytokines, such as IL-15 and interferon-gamma (IFN- $\gamma)$, further propagating the negative effects on T-cell effector functions. A more detailed understanding of the altered cytokine profile in AML has been reviewed by Binder et al [32].

Other soluble factors related to different metabolic pathways have also been described to modulate the TME in leukemia. High levels of arginase II in plasma of AML patients were shown to impair T-cell proliferation and to polarize monocytes toward an immunosuppressive M2-like phenotype. In addition, increased arginine metabolism inhibited the proliferation of hematopoietic progenitors, contributing to a wider suppressive TME [33]. Together with arginine II, upregulation of the inducible nitric oxide synthase (iNOS) by AML blasts correlated to inhibition of Tcell proliferation, increase in Tregs, and decreased number of NKT cells [34]. Among the most recently studied metabolites in the tumors are fatty acids and lipid mediators derived from fatty acids. Emerging data suggest that targeting lipid pathways may restore an active immune milieu in AML [35]. In particular, AML blasts can metabolize both glucose and fatty acids, released by surrounding stromal adipocytes, to derive acetyl-CoA to drive the Krebs cycle and oxidative phosphorylation (OXPHOS) for ATP production. Notably, LSCs in the AML niche express the fatty acid transporter CD36, and induce lipolysis in BM adipocytes to fuel fatty acid oxidation (FAO) in leukemic cells [36].

\section{AML blasts escape NK cell recognition}

NK-mediated tumor recognition is MHC-independent and is governed by the interaction of inhibitory and activating receptors on NKs and several ligands expressed on the surface of tumor cells. The graft-versus-leukemia effect mediated by alloreactive NKs in patients receiving haploidentical HSCT represented one of the first evidence that NKs can target and kill residual AML blasts. However, mechanisms of NK-cell evasion and escape by AML blasts have been documented and include an altered expression of NK-cell ligands caused by epigenetic changes, such as incorrect hypermethylation of genes encoding ligands for the activating receptor NKG2D (NKG2DL), namely MICA, ULBP1, ULBP2, and ULBP3 genes [37]. Notably, NKG2DL-negative leukemic cells that escaped the NK-cell immune recognition were shown to have an immature morphology and molecular and functional stemness characteristics, further indicating how AML LSCs and immune evasion are intertwined [38]. Moreover, AML blasts were shown to release a soluble form of NKG2DL (sNKG2DL), through cleavage by metalloproteases or into exosomes, causing the downregulation of NKG2D receptor on NKs and impairing their cytotoxic activity. AML blasts express high levels of ligands, such as CD112 and CD155, that cause a decrease in their activating receptor DNAM-1 on NKs, ultimately leading to an altered degranulation of NKs and impaired cytotoxic activity $[39,40]$. AML blasts may also escape NKs by induction of co-inhibitory receptors in NKs that include TIGIT, which inhibits IFN- $\gamma$ release [41]. High TIGIT expression at engraftment has been associated with a reduced number of NKs in the BM, reduced incidence of acute graft-versus-host disease, and poor survival [42].

\section{AML blasts increase myeloid-derived suppressor cells and tumor-associated macrophages}

Myeloid-derived suppressor cells (MDSCs) cause T-cell tolerance through multiple mechanisms that include expression of $\mathrm{V}$ domain lg suppressor of T-cell activation (VISTA), PD-L1, IDO1, arginase, and production of reactive oxygen species (ROS), peroxynitrate, and multiple cytokines (TGF- $\beta$ and IL-10) [43]. AML blasts can promote MDSCs expansion by releasing extracellular vesicles (EVs) containing the oncoprotein MUC1, which, in turn, increases c-myc expression in EVs through microRNA miR34a, leading to MDSCs proliferation [44]. Recently, the Akt/mTOR pathway has been shown to play a critical role in the AML-EVinduced phenotypical and functional transition from monocytes to MDSCs. Monocytes engulfing AML-derived EVs acquire the typical $\mathrm{CD} 14^{+} \mathrm{HLA}-\mathrm{DR}{ }^{\text {low }}$ inhibitory phenotype and upregulate expression of genes characteristic for MDSCs, such as S100A8/9 and CEBP $\beta$ [45]. In AML patients, it has been reported that MDSCs were more abundant in BM and in PB compared with healthy controls [44]. There is also an association between Tregs and MDSCs numbers in myelodysplastic syndrome, which correlates with a higher risk of transformation to $A M L$, indicating a potential role for MDSCs in AML progression [46].

Macrophages are critical cellular components of the immunosuppressive TME. The intrinsic plasticity of macrophages renders this cell subset particularly susceptible to tissue-specific regulation. Within the TME, tumor-associated macrophages (TAMs) are generally defined as M2 macrophages, and are characterized by anti-inflammatory activity by secreting arginase, metalloproteinases, TGF- $\beta$, IL-10, and other cytokines that cause immune suppression, angiogenesis and tissue repair [47]. Al-Matary et al. reported that TAMs are elevated in the BM of AML patients compared to healthy donors. Moreover, AML blasts can directly drive TAMs to an M2-like phenotype in the BM and spleen of tumor-bearing mice [48].

\section{Stromal and vascular niches promote resistance to immunotherapy}

The TME in AML causes resistance to conventional chemotherapy and suppresses anti-tumor immune responses. In fact, leukemiaassociated remodeling within the AML niche, including changes associated with increased hypoxia and inflammation as well as metabolic reprogramming, facilitate immune evasion and activation of survival pathways favoring AML progression (Fig. 2) [49].

\section{Immunosuppressive properties of mesenchymal stromal cells} in AML

Mesenchymal stromal cells (MSCs) physiologically display a unique immune regulation ability by inhibiting/reprogramming the 


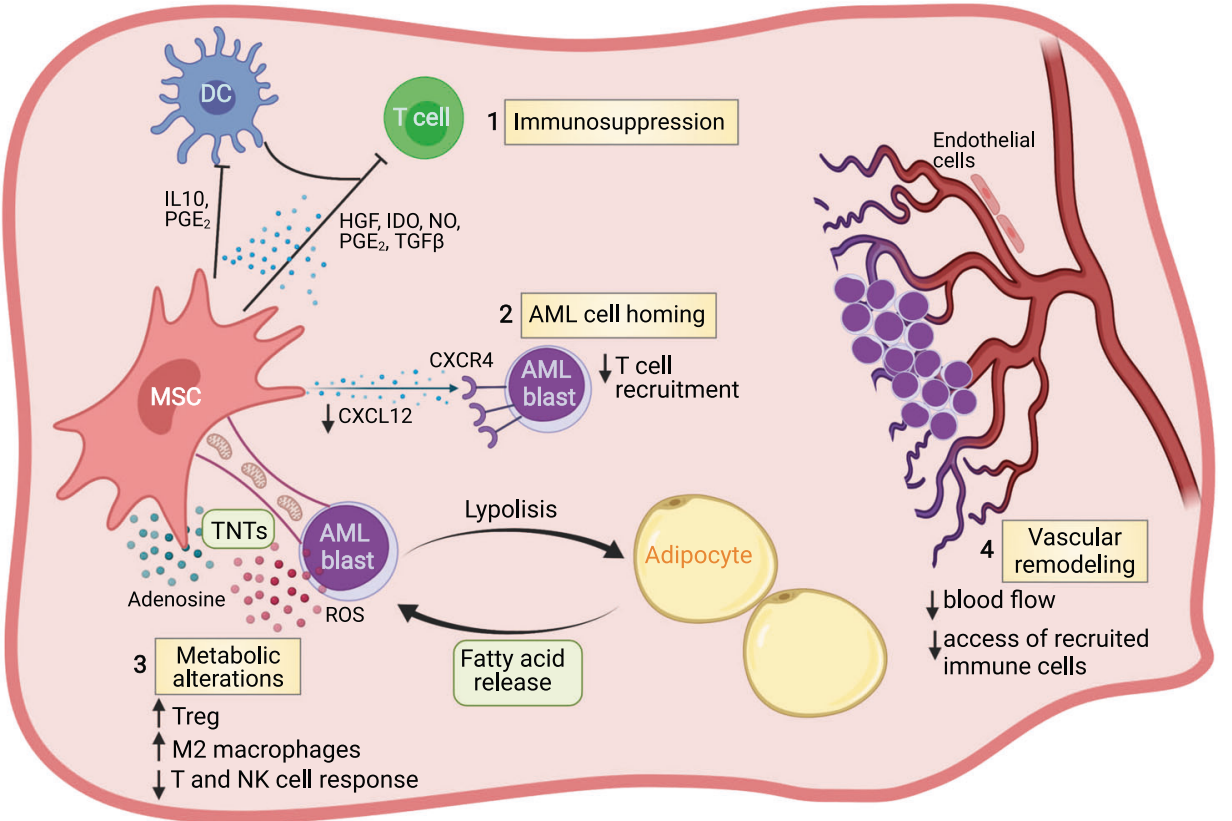

Fig. 2 Contributions of non-hematopoietic cells in the bone marrow niche to AML immune escape. Representative mechanisms by which AML-reprogrammed niche cells can promote immune evasion. Mesenchymal stromal cells (MSCs) can regulate the immune response in the leukemic BM microenvironment by secreting a plethora of inhibitory factors, as soluble molecules or as a component of exosomes (1). These factors can inhibit cell proliferation, cytolysis, and production of anti-leukemia cytokines by effector lymphocytes. MSCs mainly through the altered production of CXCL12, interacting with CXCR4, can influence the fate of leukemic cells by triggering their proliferation, spread, and survival and regulate leukocyte migration to the BM niche (2). MSCs and adipocytes regulate the leukemia cells' metabolism (3). The mitochondrial transfer has recently been appreciated to be a mechanism of intercellular communication associated with chemoresistance and potentially also with immune resistance. Tunneling nanotubules (TNTs) appear to be the primary exchange route used by MSCs to donate mitochondria to AML blasts, boosting oxidative phosphorylation and consequently ROS production which is used by AML blasts as a strategy to evade anti-leukemic effector lymphocytes. A reciprocal relationship occurs between AML blasts and adipocytes wherein malignant cells induce lipolysis from adipocytes and, in turn, adipocytes release fatty acids, which are used as an energy source by malignant hematopoietic cells. Fatty acid oxidation seems to promote the development and activity of immunosuppressive immune cells, such as Tregs and M2 macrophages. The dramatic increase in BM vascular permeability and decrease of blood flow that coincides with leukemic growth can alter the ability of T cells to home, adhere, and extravasate into the leukemic reservoir (4). Figure created with Biorender.

activation, proliferation, and function of both adaptive and innate immune cells, as extensively recently reviewed [50]. The role of MSCs in inhibiting innate and adaptive immunity in hematological malignancies, and in particular in AML, is under active investigation. Vasold and colleagues have reported that AML blasts cultured with MSCs are less susceptible to NK cell-mediated killing and that the stromal-induced protection in AML was cell-cell contactdependent [51]. Toll-like receptor (TLR) 4 may contribute to the MSC-induced inhibition of NK cell function. Sorted TLR4 ${ }^{+}$MSCs derived from AML patients decreased NK cell proliferation and cytotoxicity, and this effect was enhanced by the activation of the TLR4 pathway following lipopolysaccharides treatment $[52,53]$.

The inhibitory effect of MSCs isolated from AML patients is further supported by their capacity to induce Tregs and upregulate IDO1 [54, 55]. Similarly, MSCs isolated from patients with myelodysplastic syndrome inhibit DC functions through increased production of TGF- $\beta$ [56]. Other studies reported that AML-derived MSCs are more immunosuppressive and anti-inflammatory than MSCs isolated from healthy donors, showing enhanced suppression of lymphocytes proliferation in vitro and diminished secretion of pro-inflammatory cytokines such as IL-10 [57]. It has also been shown that different clinical/cytogenetic AML subgroups may associate with different profiles of MSCs. Lopes et al. reported that MSCs in AML patients at diagnosis are characterized by high levels of vascular endothelial growth factor A (VEGFA), chemokine ligand 12 (CXCL12), prostaglandin E2 (PGE 2$)$, IDO1, IL-1 $\beta, I L-6$, and IL-32 and decrease of IL-10 compared to MSCs collected at the time of disease relapse indicating that MSCs as TAMs are plastic cells that may respond to environmental stimuli [58].
Immunosuppression mediated by MSCs can be further exacerbated by the capacity of AML blasts to generate an inflamed TME. Thus, modifications of the inflammatory status induced by therapy can reshape the immunomodulatory activity of MSCs. In patients with juvenile myelomonocytic leukemia, MSCs showed differential mRNA expression, including genes involved in immunomodulation, that normalized when disease remission was achieved after HSCT [59]. If MSCs can affect immune-based therapies remains to be elucidated. The cytokine storm observed in patients treated with CAR T cells can potentially elicit the immunosuppressive activity of MSCs and cause cell death of MSCs, which is required for triggering their immunosuppressive effects [60]. Recent data showing that MSCs inhibit T-cell responses but do not compromise CD19-specific CAR T cell activity seems indicating that the potent effector function of CAR T cells may overcome the inhibitory effects of MSCs, but additional studies are needed to mechanistically highlight this phenomenon [61].

\section{AML niche shows altered immune cell homing}

CXCL12 expressed by BM stromal cells and its receptor CXC receptor 4 (CXCR4) play a key role in the migration of LSCs to the BM niche. High expression of CXCR4 on AML blasts has been shown to predict poor prognosis [62]. The CXCL12/CXCR4 axis can also activate pathways that favor the survival, growth, and chemotherapy resistance of AML blasts [63]. CXCL12 expression seems to be reduced in MSCs in AML, fostering the migration of CXCR4-overexpressing malignant LSCs versus normal hematopoietic stem cells (HSCs) [64]. CXCR4 is also involved in the trafficking of adoptively transferred lymphocytes or CAR T cells to the BM niche. 
Suppression in the ability of stromal cells to produce CXCL12 in the AML TME may dampen their migration and infiltration into the BM, as reported for other hematological malignancies [65].

\section{Metabolic alterations of the AML niche}

It has been established that leukemic cells present deregulated energy metabolism, which may be involved in causing immune evasion. Competition for critical nutrients such as glucose or amino acids increased release of bioactive inhibitory metabolites such as ROS, and overall microenvironmental metabolic remodeling in tumors including AML have been reported playing inhibitory effects on the immune cell subsets [66]. MSCs are capable of further triggering these metabolic alterations by increasing the bioavailability of nutrients or by the direct transfer of key machineries between cells. MSCs from AML patients have a higher propensity to differentiate into adipocytes, and the interaction between AML blasts and adipocytes in the $\mathrm{BM}$ niche creates a unique microenvironment that supports the metabolic demands of leukemia $[36,67]$. AML blasts induce hormonesensitive lipase in adipocytes and activate lipolysis, which then enable FABP4-dependent transfer of fatty acids to leukemia cells, thus enhancing FAO $[68,69]$. Fatty acid abundance can hamper effector Tcell functions and promote Tregs differentiation [70]. In fact, FAO can inhibit the activation of effector T cells by increasing PD-1 expression and inhibiting INF- $\gamma$ secretion, while promoting Treg cell generation through activation of the MAPK signaling pathway. Moreover, FAO has also a key role in polarizing M2 macrophages [71].

MSCs can transfer mitochondria to AML cells through endocytic pathways or tunneling nanotubes (TNT), a process that is further boosted by chemotherapy and associated with increased oxidative phosphorylation-derived ATP production in the recipient cells [72]. AML-derived nicotinamide adenine dinucleotide phosphate oxidase-2 (NOX2) drives the transfer of mitochondria via the generation of superoxide [73]. Recently, gap-junction interactions between AML cells and MSCs in the leukemic niche have been implicated in the regulation of leukemic cell metabolism [74]. The constitutive activation of NOX and the mitochondrial production linked to OXPHOS are the primary sources of large amounts of ROS that are particularly abundant in AML of M4 and M5 subtypes $[75,76]$. AML blasts can use ROS to evade anti-leukemic effector lymphocytes since free radicals inactivate $T$ and NK cells by triggering PARP-1 dependent apoptosis [77].

\section{Vascular niche remodeling in AML}

Solid tumors undergo significant remodeling of the blood vessels, which hinders the efficient recruitment of $T$ cells to the tumor site [78]. Furthermore, hypoxia secondary to poor perfusion contributes to inhibit T and NK cells through the activation of their adenosine A2 receptors by the abundant adenosine present in the hypoxic environment [79]. Indeed, extracellular ATP is markedly increased in the AML niche [80] and it is transformed in the immunosuppressive mediator adenosine by the ectoenzymes CD73 and CD39 expressed on tumor cells, Tregs and MDSCs [81]. AML progression has been shown to cause significant remodeling of vascular endothelium mainly via nitric oxide (NO), with increased vascular permeability and decreased blood flow, which results in the formation of a hypoxic leukemia niche [82]. The endosteal BM region is the main site of this vessel loss [83]. As a consequence, several BM areas are hypoperfused and both drug biodistribution and immune cell trafficking are compromised [84, 85]. Finally, the adhesive properties of the immune cells to the endothelium are also altered due to the increased levels of E-selectin induced by the inflammation generated by AML blasts [86].

\section{COMBINATORIAL STRATEGIES TO OVERCOME AML RESISTANCE TO IMMUNOTHERAPY}

The complex immunosuppressive cell network of the AML niche can affect even the most advanced immune-based therapeutic strategies, such as ICls and CAR T cells. Combinatorial strategies aimed at overcoming multiple immunosuppressive mechanisms, as well as at targeting non-malignant components of the TME, such as stromal cells and vascular endothelium, may represent a novel way to enhance immunotherapy effectiveness.

\section{Targeting AML by combinatorial strategies}

Improving BiTEs or DART anti-leukemic activity. An illustrative clinical experience of $A M L$ escape from immunotherapeutic approaches relates to the studies with the bispecific T-cell engager $\left(\mathrm{BiTE}^{\circledR}\right)$ antibody construct $\mathrm{CD} 3 \times \mathrm{CD} 33, \mathrm{AMG} 330$. BiTEs are bispecific antibody-based molecules composed of two singlechain fragment variable (scFv) domains derived from two different antibodies, one specific for a tumor-associated antigen and the other one for $C D 3 \varepsilon$, on one polypeptide chain [87]. Treatment with AMG330 showed that the simultaneous engagement of target cells $\left(\mathrm{CD} 33^{+}\right.$AML blasts) and effector cells $\left(\mathrm{CD} 3^{+} \mathrm{T}\right.$ cells) facilitated recruitment and expansion of effector $T$ cells leading to the elimination of AML blasts even at very low effector-to-target ratios of up to 1:80 in vitro. However, engaged $\mathrm{CD} 4^{+}$and $\mathrm{CD} 8^{+}$memory T cells upregulated PD- 1, TIM-3, and LAG-3, indicating that these cells remain susceptible to checkpoint inhibition [88]. PD-1/PD-L1 blockade led to a significant increase of AMG330-mediated lysis, Tcell proliferation, and IFN- $\gamma$ secretion [89]. In a reported clinical study, 8 of 42 evaluable patients responded to AMG330 and preliminary response assessment showed that patients with high tumor burden had decreased response to AMG330 [90]. In search for other factors that might cause resistance to AMG330, Harrington et al. found that a favorable response correlated with the number of endogenous T cells, while the levels of CD33 in AML blasts, disease-risks and drug resistance did not correlate with responses [91]. The positive effects of the PD-1/PD-L1 have also been observed in studies using FLT3 BiTE, AMG427 (NCT03541369) [92].

DART, or dual-affinity retargeting antibodies, are bispecific antibodies that have increased stability and half-life compared to BiTEs. In particular, flotetuzumab, a CD123xCD3 bispecific DART, showed encouraging activity in AML patients with an objective response rate ranging between $18 \%$ and $30 \%$, but also increased incidence of cytokine release syndrome [93]. Of note, patients with early disease progression showed higher baseline levels of PD-L1 on AML blasts [94].

CAR $T$ cells in AML. The success of CAR T cell therapy in B cell malignancies has yet to be realized in AML. In addition to the identification of the most appropriate target in AML to maximize efficacy, but preventing myeloid suppression, preclinical evidence suggests that CAR T cells may be more susceptible to checkpoint inhibition in AML compared to $B$ cell malignancies. Kenderian et al. found PD-1 and TIM-3 pathways to be involved in CAR T cell loss of function in AML. Incubation of primary AML samples with CD33- or CD123-redirected CAR T cells resulted in a significant upregulation of PD-L1 on AML blasts and the combination of CAR T cells with ICls increased the anti-tumor effects of CAR T cells [95]. Our group has also recently observed upregulation of PD- 1 and TIM-3 on cytokine-induced killer cells (CIK) expressing a CD33specific CAR isolated from the BM of tumor-bearing mice nonresponding to the treatment [96].

In addition to ICls [97-99], epigenetic drugs can also be used in the attempt to restore AML ligands [37] and T-cell functions $[100,101]$ within the immunosuppressive TME [102]. CAR T cells combined with $\mathrm{ICls}$ are currently under preclinical and clinical investigation for the treatment of both solid and hematological tumors, as recently reviewed by Hosseinkhani $N$ et al. [103]. Novel bispecific CAR T cell constructs targeting both CD13 and TIM-3 have shown eradication of AML cells in xenograft models. Bispecific CAR T cells showed lower PD-1 and TIM-3 expression in the $\mathrm{BM}$, suggesting that TIM-3 targeting may have a potential 
immunomodulatory effect [104]. Baragaño Raneros A et al. observed that DNA methylation can contribute to the absence of NKG2DL expression during AML development. Treatment with inhibitors of histone deacetylase (HDACi) and DNA methyltransferase (DNMTi) was found to restore NKG2DL (MICA and ULBPs 1-3) expression in AML through the hypomethylation of TIMP3, an inhibitor of protease ADAM17, the sheddase involved in the release of soluble NKG2DL by AML cells [105]. The DNAdemethylating agent decitabine (DAC) has been recently shown to significantly enhance anti-leukemia functions of CD123-specific CAR T cells in vitro and in vivo. Transcriptomic profiling revealed that DAC treatment conferred to CD123 CAR T cells an enrichment of genes associated with naive, early memory, as well as nonexhausted T cells [100]. Moreover, the next-generation CAR design is conceived to boost the anti-tumor function by using immune agonist $[106]$ or co-stimulatory cytokines $[107,108]$, and to skew Tcell phenotype toward a stem cell/central memory state [109111]. In a recent preclinical study, Ataca Atilla et al. incorporated transgenic IL-15 to enhance the anti-AML activity of CLL-1 CAR T cells. Unexpectedly, and in contrast to the safety observed with CAR T/IL15 combination in other disease settings, IL-15-expressing CLL-1 CAR T cells induced a severe and atypical form of cytokine release syndrome (CRS), associated with high levels of circulating tumor necrosis factor-alpha (TNF-a). Combination of TNF-a blockade and elimination of CAR T cells using an inducible safety switch controlled the adverse events [112]. This study suggests that combinatorial strategies with CARs improve the anti-tumor effects in $A M L$, but a careful evaluation is fundamental to gain efficacy, whilst avoiding toxicity.

\section{Targeting the leukemic niche to improve the efficiency of immunotherapies}

The central role of stromal cells in the regulation of anti-tumor immune response stimulates the development of novel therapeutic strategies that target not only tumor cells directly, but also nonmalignant cells contributing in shaping the TME.

Targeting of MSCs can be obtained using cytotoxic drugs or drugs interfering with their immunosuppressive properties. Tyrosine kinase inhibitors can inhibit both growth and function of MSCs [113]. However, MSCs are involved in many physiological processes in the BM (e.g. HSCs maintenance and regulation) and in other organs (maintenance of the structural architecture), and depletion of MSCs may have serious side effects. How normal MSCs differ from leukemia-associated MSCs remains to be determined, and it is critical in guiding the development of specific drugs. In solid tumors, the fibroblast activation protein (FAP), a member of the serine protease family, is expressed by tumor-associated fibroblasts at higher levels than on resident fibroblasts in healthy tissue. Thus, FAP has been considered as a suitable target to eliminate tumor-associated fibroblasts. In particular, FAP-specific CAR T cells have been used to reduce tumor-cell growth, with minimal off-tumor toxicity [114]. However, the relationship between activated fibroblasts and BM MSCs remains unclear $[115,116]$. Many small-molecule inhibitors targeting IDO1, heme oxygenase-1 (HO-1), hepatocyte growth factor (HGF), arginase I and II, PGE 2 , and TGF- $\beta$ [117-119] and MSC immunomodulatory such as aminobiphosphonate zoledronate [120] have been developed opening the use of these drugs in combination with ICls and adoptive cell therapies.

The mobilization of leukemic cells from the protective BM niche is considered a promising strategy to increase their susceptibility not only to conventional chemotherapeutic agents but also to immunotherapies [121]. Small-molecule inhibitors, short peptides, and antibodies have been developed to disrupt the CXCL12/ CXCR4 axis that releases AML blasts from the BM [63], and recent findings suggest that CXCR4 antagonism can potentially synergize with immunotherapies in several clinical trials involving solid tumors.
Metabolic alterations of the leukemic niche are also potentially druggable. Targeting the fatty acid metabolism using FAO inhibitors may increase not only the efficacy of chemotherapeutic agents, as shown by Farge et al. by combining etomoxir and cytarabine [122], but also boost adoptively transferred T cells [71]. Although etomoxir is no longer used clinically due to its side effects [123], other FAO inhibitors, including avocatin B, exhibit similar inhibitory effects on leukemia cell metabolism [124]. The conversion of ATP in adenosine in the AML microenvironment limits anti-tumor immunity through the suppression of multiple immune subsets including T cells. Indeed, genetic depletion of the adenosine $2 \mathrm{~A}$ receptor which is over-expressed by activated CAR $T$ cells has been found to enhance their anti-tumor function $[125,126]$.

Commonly used chemotherapeutics such as cytarabine, etoposide and doxorubicin are agents that promote mitochondria uptake by AML cells [75]. Consequently, resistant clones could have increased oxidative metabolism and produce a large amount of ROS that can, in turn, inactivate T cells and NKs. Several approaches have been used to disrupt mitochondria transfer by blocking TNTs, endocytosis, or superoxide. The surface molecule CD38 is critical for the transport of mitochondria from MSCs to AML cells [127]. Daratumumab, a monoclonal anti-CD38 antibody approved for the treatment of multiple myeloma, was shown to block the delivery of mitochondria to AML cells, decrease the oxygen consumption rate, and inhibit the growth of leukemic cells $[128,129]$. Main regulators of mitochondrial biogenesis and activity including PGC-1a and NOX2 are also promising targets. Marley et al. showed that inactivation of PGC-1a by knockdown or by reduction in superoxide levels with $\mathrm{N}$-acetylcysteine impaired mitochondrial transfer [73, 130]. Gap junctions are also shown to mediate mitochondria transfer of MSCs. Blocking connexin-43 gap-junction formation had no effect on cytoplasmic transfer, but reduced mitochondria transfer [131].

Finally, remodeling the dysfunctional tumor vasculature in $\mathrm{AML}$ and reversing hypoxia may increase drug delivery and enhance Tcell function. In this sense, NOS inhibitors can function to normalize the altered BM vascular permeability [82]. NOS inhibitors have been developed for several applications, many of which are under clinical investigation. A specific example is the development of a peptide that mimics the endogenous inhibition function of caveolin-1 and selectively acts on endothelial NOS3 [132].

\section{CONCLUSION AND FUTURE PERSPECTIVES}

Immunotherapy offers the possibility of more specific and less long-term toxic therapy in AML. The growing attention to new immunotherapy strategies together with a greater elucidation of the AML pathophysiology has led to understanding how the TME plays key roles in hindering therapeutic efficacy and in modulating toxicity.

Transcriptomic signatures have been recently used to stratify AML patients into immune-infiltrated and immune-depleted disease revealing critical differences in immune gene expression across age groups and molecular disease subtypes [5]. Of utmost importance, a novel precision medicine-based conceptual framework was described by evaluating the response to the CD123xCD3 DART flotetuzumab in relapsed/refractory AML patients. Specifically, T cell-targeting immunotherapy has been found to be beneficial in subgroups of patients with immune-infiltrated TME. Furthermore, since flotetuzumab increases expression of PD-L1 in AML blast, there is strong rationale for conceiving clinical studies with sequential flotetuzumab and ICls in AML [94]. Immunological stratification of pre-treatment BM samples combined with cytogenetic and mutational information may define AML patients who will potentially have greatest benefit from immunotherapies.

The development of preclinical models that faithfully recapitulate the TME of the human AML remains instrumental to dissect 
the mechanism underlining the formation of the TME and to test novel therapeutic approaches. Artificial 3D microenvironment recreating the topology of BM with the stromal and vascular niche components, such as BM-on-a-chip platforms, can offer a powerful tool [133]. Moreover, the in situ mapping of different subpopulations in the human BM would allow a better definition of the cell subsets involved and of stromal cell-specific markers that could lead to the development of selective stromal-targeted therapies $[134,135]$

The future of immunotherapies foresees combinatorial strategies based not only on the possibility to increase targeting efficacy but also on the modulation of the immune escape mechanisms generated within the TME. Finally, precise identification of the immune escape mechanisms in individual AML patients will allow for personalized immunotherapy based on specific immune signatures.

\section{REFERENCES}

1. Guo R, Lü M, Cao F, Wu G, Gao F, Pang H, et al. Single-cell map of diverse immune phenotypes in the acute myeloid leukemia microenvironment. Biomark Res. 2021;9:1-16.

2. Bailur JK, McCachren SS, Pendleton K, Vasquez JC, Lim HS, Duffy A et al. Riskassociated alterations in marrow T cells in pediatric leukemia. JCI Insight 2020;5.

3. Brück O, Dufva O, Hohtari H, Blom S, Turkki R, llander M, et al. Immune profiles in acute myeloid leukemia bone marrow associate with patient age, T-cell receptor clonality, and survival. Blood Adv. 2020;4:274-86.

4. Chretien A-S, Devillier R, Granjeaud S, Cordier C, Demerle C, Salem N, et al. Highdimensional mass cytometry analysis of NK cell alterations in AML identifies a subgroup with adverse clinical outcome. Proc Natl Acad Sci. 2021;118: e2020459118.

5. Vadakekolathu J, Minden MD, Hood T, Church SE, Reeder S, Altmann H et al. Immune landscapes predict chemotherapy resistance and immunotherapy response in acute myeloid leukemia. Sci Transl Med 2020;12.

6. Toffalori C, Zito L, Gambacorta V, Riba M, Oliveira G, Bucci G, et al. Immune signature drives leukemia escape and relapse after hematopoietic cell transplantation. Nat Med. 2019;25:603-11.

7. Jan M, Leventhal MJ, Morgan EA, Wengrod JC, Nag A, Drinan SD, et al. Recurrent genetic HLA loss in AML relapsed after matched unrelated allogeneic hematopoietic cell transplantation. Blood Adv. 2019;3:2199-204.

8. Christopher MJ, Petti AA, Rettig MP, Miller CA, Chendamarai E, Duncavage EJ, et al. Immune escape of relapsed aml cells after allogeneic transplantation. $\mathrm{N}$ Engl J Med. 2018;379:2330-41.

9. Stölzel F, Hackmann K, Kuithan F, Mohr B, Füssel M, Oelschlägel U, et al. Clonal evolution including partial loss of human leukocyte antigen genes favoring extramedullary acute myeloid leukemia relapse after matched related allogeneic hematopoietic stem cell transplantation. Transplantation. 2012;93:744-9.

10. Taghiloo S, Asgarian-Omran H. Immune evasion mechanisms in acute myeloid leukemia: a focus on immune checkpoint pathways. Crit Rev Oncol Hematol 2021;157:103164.

11. Kikushige $Y$, Shima $T$, Takayanagi S, Urata S, Miyamoto $T$, Iwasaki $H$, et al. Article TIM-3 is a promising target to selectively kill acute myeloid leukemia stem cells. Stem Cell. 2010;7:708-17.

12. Kikushige $Y$, Miyamoto $T$. Identification of TIM-3 as a leukemic stem cell surface molecule in primary acute myeloid leukemia. Oncology 2015;89:28-32.

13. Kong Y, Zhang J, Claxton DF, Ehmann WC, Rybka WB, Zhu L, et al. PD-1hiTIM-3+ $T$ cells associate with and predict leukemia relapse in AML patients post allogeneic stem cell transplantation. Blood Cancer J. 2015;5:330.

14. Darwish NH, Sudha T, Godugu K, Elbaz O, Abdelghaffar HA, Hassan EE et al. Acute myeloid leukemia stem cell markers in prognosis and targeted therapy: potential impact of BMI-1, TIM-3 and CLL-1. Oncotarget. 2016;7:57811-20.

15. Kamal AM, Nabih NA, Elleboudy NS, Radwan SM. Expression of immune check point gene TIM-3 in patients newly diagnosed with acute myeloid leukemia: significance and impact on outcome. Oncol Lett. 2021;21:1-9.

16. Jan M, Chao MP, Cha AC, Alizadeh AA, Gentles AJ, Weissman IL, et al. Prospective separation of normal and leukemic stem cells based on differential expression of TIM3, a human acute myeloid leukemia stem cell marker. Proc Natl Acad Sci USA. 2011;108:5009-14

17. Wang $M, B$ J, Zhou M, Sido J, Lin Y, Liu G, et al. CD8+ T cells expressing both PD-1 and TIGIT but not CD226 are dysfunctional in acute myeloid leukemia (AML) patients. Clin Immunol. 2018;190:64-73.

18. Gao J, Zheng Q, Xin N, Wang W, Zhao C. CD155, an onco-immunologic molecule in human tumors. Cancer Sci. 2017;108:1934-8.
19. Stamm H, Wellbrock J, Fiedler W. Interaction of PVR/PVRL2 with TIGIT/DNAM-1 as a novel immune checkpoint axis and therapeutic target in cancer. Mamm Genome 2018;29:694-702.

20. Radwan S, Elleboudy N, Nabih N, Kamal A. AML-273: the immune checkpoints CTLA-4 and LAG-3 expression is upregulated in acute myeloid leukemia. Clin Lymphoma Myeloma Leuk. 2020;20:S198.

21. Majeti R, Chao MP, Alizadeh AA, Pang WW, Jaiswal S, Gibbs KD, et al. CD47 is an adverse prognostic factor and therapeutic antibody target on human acute myeloid leukemia stem cells. Cell. 2009;138:286-99.

22. Chao MP, Takimoto CH, Feng DD, McKenna K, Gip P, Liu J, et al. Therapeutic Targeting of the Macrophage Immune Checkpoint CD47 in Myeloid Malignancies. Front Oncol 2020;9:1380.

23. Le Dieu R, Taussig DC, Ramsay AG, Mitter R, Miraki-Moud F, Fatah R et al. Peripheral blood T cells in acute myeloid leukemia (AML) patients at diagnosis have abnormal phenotype and genotype and form defective immune synapses with AML blasts. Blood. 2009;114:3909-16.

24. Lim SH, Worman $\mathrm{CP}$, Jewell AP, Goldstone AH. Cellular cytotoxic function and potential in acute myelogenous leukaemia. Leuk Res. 1991;15:641-4.

25. Curti A, Pandolfi S, Valzasina B, Aluigi M, Isidori A, Ferri E et al. Modulation of tryptophan catabolism by human leukemic cells results in the conversion of CD25 into CD25 T regulatory cells. Blood. 2007;109:2871-7.

26. Ersvaer E, Liseth K, Skavland J, Gjertsen BT, Bruserud $\varnothing$. Intensive chemotherapy for acute myeloid leukemia differentially affects circulating TC1, TH1, TH17 and TREGcells. BMC Immunol 2010;11:38.

27. Shenghui $Z$, Yixiang $H$, Jianbo $W$, Kang $Y$, Laixi $B, Y a n Z$, et al. Elevated frequencies of $C D 4+C D 25+C D 127$ lo regulatory $T$ cells is associated to poor prognosis in patients with acute myeloid leukemia. Int J Cancer. 2011;129:1373-81.

28. Chen W, Jin W, Hardegen N, Lei K-J, Li L, Marinos N, et al. Conversion of peripheral CD4 CD25 naive T cells to CD4 CD25 regulatory T cells by TGF-induction of transcription factor Foxp3. J Exp Med J Exp Med. 2003;198:1875-86.

29. R.Walker M, Kasprowicz DJ, Gersuk VH, Bènard A, Van Landeghen M, Buckner JH, et al. Induction of FoxP3 and acquisition of $\mathrm{T}$ regulatory activity by stimulated human CD4+CD25- T cells. J Clin Invest. 2003;112:1437-43.

30. Cools N, Van Tendeloo VFI, Smits ELJM, Lenjou M, Nijs G, Van Bockstaele DR, et al. Immunosuppression induced by immature dendritic cells is mediated by TGF- $\beta /$ IL-10 double-positive CD4+ regulatory $T$ cells. J Cell Mol Med. 2008;12:690-700.

31. Folgiero V, Goffredo BM, Filippini P, Masetti R, Bonanno G, Caruso R, et al. Indoleamine 2,3-dioxygenase 1 (IDO1) activity in leukemia blasts correlates with poor outcome in childhood acute myeloid leukemia. Oncotarget. 2014;5:2052-64.

32. Binder S, Luciano M, Horejs-Hoeck J. The cytokine network in acute myeloid leukemia (AML): A focus on pro- and anti-inflammatory mediators. Cytokine Growth Factor Rev. 2018;43:8-15.

33. Mussai F, Santo C De, Abu-Dayyeh I, Booth S, Quek L, Mcewen-Smith RM et al. Acute myeloid leukemia creates an arginase-dependent immunosuppressive microenvironment. Blood. 2013;122:749-58.

34. Jacamo R, Hoang N-M, Al Rawi A, Ly C, Parihar R, McQueen T, et al. Upregulation of iNOS in AML blasts creates an immunosuppressive microenvironment, inhibits T-cell proliferation and transforms T-cells towards a tumor-tolerating phenotype. Blood. 2017;130:2443-2443.

35. Tabe Y, Konopleva M, Andreeff M Fatty Acid Metabolism, Bone Marrow Adipocytes, and AML. Front Oncol. 2020;10:155.

36. Ye H, Woolthuis $C M$, Stranahan AW, Park CY, Minhajuddin M, Gasparetto M, et al Leukemic stem cells evade chemotherapy by metabolic adaptation to an adipose tissue niche. Cell Stem Cell. 2016;19:23-37.

37. Baraganõ Raneros A, Martín-Palanco V, Fernandez AF, Rodriguez RM, Fraga MF, Lopez-Larrea C, et al. Methylation of NKG2D ligands contributes to immune system evasion in acute myeloid leukemia. Genes Immun. 2015;16:71-82.

38. Paczulla AM, Rothfelder K, Raffel S, Konantz M, Steinbacher J, Wang $\mathrm{H}$, et al. Absence of NKG2D ligands defines leukaemia stem cells and mediates their immune evasion. Nature. 2019;572:254-9.

39. Costello RT, Sivori S, Marcenaro E, Lafage-Pochitaloff $M$, Mozziconacci MJ, Reviron D, et al. Defective expression and function of natural killer celltriggering receptors in patients with acute myeloid leukemia. Blood. 2002;99:3661-7.

40. Sanchez-Correa B, Gayoso I, Bergua JM, Casado JG, Morgado S, Solana R, et al. Decreased expression of DNAM-1 on NK cells from acute myeloid leukemia patients. Immunol Cell Biol. 2012;90:109-15.

41. Kong Y, Zhu L, Schell TD, Zhang J, Claxton DF, Ehmann WC, et al. T-cell immunoglobulin and ITIM domain (TIGIT) associates with CD8+ T-cell exhaustion and poor clinical outcome in AML patients. Clin Cancer Res. 2016;22:3057-66.

42. Hattori N, Kawaguchi Y, Sasaki Y, Shimada S, Murai S, Abe M, et al. Monitoring TIGIT/DNAM-1 and PVR/PVRL2 immune checkpoint expression levels in 
allogeneic stem cell transplantation for acute myeloid leukemia. Biol Blood Marrow Transpl. 2019;25:861-7.

43. Yang Y, Li C, Liu T, Dai X, Bazhin AV. Myeloid-derived suppressor cells in tumors: from mechanisms to antigen specificity and microenvironmental regulation. Front Immunol 2020;11:1371.

44. Pyzer AR, Stroopinsky D, Rajabi H, Washington A, Tagde A, Coll M, et al. MUC1mediated induction of myeloid-derived suppressor cells in patients with acute myeloid leukemia. Blood. 2017;129:1791-801.

45. Tohumeken S, Baur R, Bottcher M, Stoll A, Loschinski R, Panagiotidis K, et al. Palmitoylated proteins on AML-derived extracellular vesicles promote myeloidderived suppressor cell differentiation via TLR2/Akt/mTOR signaling. Cancer Res. 2020;80:3663-76.

46. Kittang AO, Kordasti S, Sand KE, Costantini B, Kramer AM, Perezabellan P et al. Expansion of myeloid derived suppressor cells correlates with number of $T$ regulatory cells and disease progression in myelodysplastic syndrome. Oncoimmunology. 2015;5:e1062208.

47. Mantovani A, Sozzani S, Locati M, Allavena P, Sica A. Macrophage polarization: Tumor-associated macrophages as a paradigm for polarized M2 mononuclear phagocytes. Trends Immunol. 2002;23:549-55.

48. Al-Matary YS, Botezatu L, Opalka B, Hönes JM, Lams RF, Thivakaran A, et al. Acute myeloid leukemia cells polarize macrophages towards a leukemia supporting state in a growth factor independence 1 dependent manner. Haematologica. 2016;101:1216-27.

49. Méndez-Ferrer S, Bonnet D, Steensma DP, Hasserjian RP, Ghobrial IM, Gribben JG, et al. Bone marrow niches in haematological malignancies. Nat Rev Cancer 2020;20:285-98.

50. Müller $L$, Tunger $A$, Wobus $M$, von Bonin $M$, Towers $R$, Bornhäuser $M$ et al. Immunomodulatory properties of mesenchymal stromal cells: an update. Front Cell Dev Biol. 2021;9:637725.

51. Vasold J, Wagner M, Drolle H, Deniffel C, Kütt A, Oostendorp R, et al. The bone marrow microenvironment is a critical player in the NK cell response against acute myeloid leukaemia in vitro. Leuk Res. 2015;39:257-62.

52. Tomchuck SL, Zwezdaryk KJ, Coffelt SB, Waterman RS, Danka ES, Scandurro AB. Toll-like receptors on human mesenchymal stem cells drive their migration and immunomodulating responses. Stem Cells. 2008;26:99-107.

53. Lu Y, Liu J, Liu Y, Qin Y, Luo Q, Wang Q, et al. TLR4 plays a crucial role in MSCinduced inhibition of NK cell function. Biochem Biophys Res Commun. 2015;464:541-7.

54. Corradi G, Baldazzi C, Očadlíková D, Marconi G, Parisi S, Testoni N et al. Mesenchymal stromal cells from myelodysplastic and acute myeloid leukemia patients display in vitro reduced proliferative potential and similar capacity to support leukemia cell survival. Stem Cell Res Ther. 2018;9:271.

55. Mansour I, Zayed RA, Said F, Latif LA. Indoleamine 2,3-dioxygenase and regulatory $T$ cells in acute myeloid leukemia. Hematology. 2016;21:447-53.

56. Wang Z, Tang X, Xu W, Cao Z, Sun L, Li W, et al. The different immunoregulatory functions on dendritic cells between mesenchymal stem cells derived from bone marrow of patients with low-risk or high-risk myelodysplastic syndromes. PLoS One. 2013;8:2-9.

57. Diaz de la Guardia R, Lopez-Millan B, Lavoie JR, Bueno C, Castaño J, GómezCasares $M$, et al. Detailed characterization of mesenchymal stem/stromal cells from a large cohort of aml patients demonstrates a definitive link to treatment outcomes. Stem Cell Rep. 2017;8:1573-86.

58. Lopes MR, Pereira JKN, De Melo Campos P, Machado-Neto JA, Traina F, Saad STO, et al. De novo AML exhibits greater microenvironment dysregulation compared to AML with myelodysplasia-related changes. Sci Rep. 2017;7:1-12.

59. Calkoen FGJ, Vervat C, Eising E, Vijfhuizen LS, 't Hoen PBAC, van den Heuvel-Eibrink $\mathrm{MM}$, et al. Gene-expression and in vitro function of mesenchymal stromal cells are affected in juvenile myelomonocytic leukemia. Haematologica. 2015;100:1434-41.

60. Galleu A, Riffo-Vasquez Y, Trento C, Lomas C, Dolcetti L, Cheung TS et al. Apoptosis in mesenchymal stromal cells induces in vivo recipient-mediated immunomodulation. Sci Transl Med. 2017;9:eaam7828.

61. Zanetti SR, Romecin PA, Vinyoles M, Juan M, Fuster JL, Cámos M, et al. Bone marrow MSC from pediatric patients with B-ALL highly immunosuppress T-cell responses but do not compromise CD19-CAR T-cell activity. J Immunother Cancer. 2020;8:1-13.

62. Spoo AC, Lübbert M, Wierda WG, Burger JA. CXCR4 is a prognostic marker in acute myelogenous leukemia. Blood. 2007;109:786-91.

63. Cancilla D, Rettig MP, DiPersio JF Targeting CXCR4 in AML and ALL. Front Oncol. 2020;10:1672.

64. Hanoun M, Zhang D, Mizoguchi T, Pinho S, Pierce H, Kunisaki Y, et al. Acute myelogenous leukemia-induced sympathetic neuropathy promotes malignancy in an altered hematopoietic stem cell niche. Cell Stem Cell. 2014;15:365-75.

65. Ponzetta A, Benigni $G$, Antonangeli $F$, Sciumè $G$, Sanseviero $E$, Zingoni $A$, et al. Multiple myeloma impairs bone marrow localization of effector natural killer cells by altering the chemokine microenvironment. Cancer Res. 2015;75:4766-77.
66. Mougiakakos D. The induction of a permissive environment to promote T cell immune evasion in acute myeloid leukemia: the metabolic perspective. Front Oncol. 2019;9:1-9.

67. Azadniv M, Myers JR, McMurray HR, Guo N, Rock P, Coppage ML, et al. Bone marrow mesenchymal stromal cells from acute myelogenous leukemia patients demonstrate adipogenic differentiation propensity with implications for leukemia cell support. Leukemia. 2020;34:391-403.

68. Shafat MS, Oellerich T, Mohr S, Robinson SD, Edwards DR, Marlein CR, et al. Leukemic blasts program bone marrow adipocytes to generate a protumoral microenvironment. Blood. 2017;129:1320-32.

69. Tabe Y, Yamamoto S, Saitoh K, Sekihara K, Monma N, Ikeo K, et al. Bone marrow adipocytes facilitate fatty acid oxidation activating AMPK and a transcriptional network supporting survival of acute monocytic leukemia cells. Cancer Res. 2017;77:1453-64.

70. Michalek RD, Gerriets VA, Jacobs SR, Macintyre AN, Maclver NJ, Mason EF, et al. Cutting edge: distinct glycolytic and lipid oxidative metabolic programs are essential for effector and regulatory CD4 $+\mathrm{T}$ cell subsets. J Immunol. 2011;186:3299-303.

71. O'Neill LAJ, Kishton RJ, Rathmell J. A guide to immunometabolism for immunologists. Nat Rev Immunol. 2016;16:553-65.

72. Moschoi R, Imbert V, Nebout M, Chiche J, Mary D, Prebet T, et al. Protective mitochondrial transfer from bone marrow stromal cells to acute myeloid leukemic cells during chemotherapy. Blood. 2016;128:253-64.

73. Marlein CR, Zaitseva L, Piddock RE, Robinson SD, Edwards DR, Shafat MS, et al. NADPH oxidase- 2 derived superoxide drives mitochondrial transfer from bone marrow stromal cells to leukemic blasts. Blood. 2017;130:1649-60.

74. Kouzi F, Zibara K, Bourgeais J, Picou F, Gallay N, Brossaud J, et al. Disruption of gap junctions attenuates acute myeloid leukemia chemoresistance induced by bone marrow mesenchymal stromal cells. Oncogene. 2020;39:1198-212.

75. Hole PS, Zabkiewicz J, Munje C, Newton Z, Pearn L, White P, et al. Overproduction of NOX-derived ROS in AML promotes proliferation and is associated with defective oxidative stress signaling. Blood. 2013;122:3322-30.

76. Farge T, Saland E, de Toni F, Aroua N, Hosseini M, Perry R, et al. Chemotherapyresistant human acute myeloid leukemia cells are not enriched for leukemic stem cells but require oxidative metabolism. Cancer Disco. 2017;7:716-35.

77. Aurelius J, Thorén FB, Akhiani AA, Brune $M$, Palmqvist $L$, Hansson $M$, et al. Monocytic AML cells inactivate antileukemic lymphocytes: Role of NADPH oxidase/gp91 phox expression and the PARP-1/PAR pathway of apoptosis. Blood. 2012;119:5832-7.

78. Ager A, Watson HA, Wehenkel SC, Mohammed RN. Homing to solid cancers: a vascular checkpoint in adoptive cell therapy using CAR T-cells. Biochem Soc Trans. 2016;44:377-85.

79. Vijayan D, Young A, Teng MWL, Smyth MJ. Targeting immunosuppressive adenosine in cancer. Nat Rev Cancer. 2017;17:709-24.

80. He X, Wan J, Yang X, Zhang X, Huang D, Li X et al. Bone marrow niche ATP levels determine leukemia-initiating cell activity via P2X7 in leukemic models. J Clin Invest. 2021;131:e140242.

81. Beavis PA, Stagg J, Darcy PK, Smyth MJ. CD73: A potent suppressor of antitumor immune responses. Trends Immunol. 2012;33:231-7.

82. Passaro D, Di Tullio A, Abarrategi A, Rouault-Pierre K, Foster K, Ariza-McNaughton L, et al. Increased vascular permeability in the bone marrow microenvironment contributes to disease progression and drug response in acute myeloid leukemia. Cancer Cell. 2017;32:324-41.e6.

83. Duarte D, Hawkins ED, Akinduro O, Ang H, De Filippo K, Kong IY, et al. Inhibition of endosteal vascular niche remodeling rescues hematopoietic stem cell loss in AML. Cell Stem Cell. 2018;22:64-77.e6.

84. Carmeliet $P$, Jain RK. Principles and mechanisms of vessel normalization for cancer and other angiogenic diseases. Nat Rev Drug Disco. 2011;10:417-27.

85. Rytelewski M, Haryutyunan K, Nwajei F, Shanmugasundaram M, Wspanialy P, Zal $M A$, et al. Merger of dynamic two-photon and phosphorescence lifetime microscopy reveals dependence of lymphocyte motility on oxygen in solid and hematological tumors. J Immunother Cancer. 2019;7:1-13.

86. Barbier V, Erbani J, Fiveash C, Davies JM, Tay J, Tallack MR et al. Endothelial Eselectin inhibition improves acute myeloid leukaemia therapy by disrupting vascular niche-mediated chemoresistance. Nat Commun. 2020;11:2042.

87. Nagorsen D, Baeuerle PA. Immunomodulatory therapy of cancer with T cellengaging BiTE antibody blinatumomab. Exp Cell Res 2011;317:1255-60.

88. Krupka C, Kufer P, Kischel R, Zugmaier G, Lichtenegger FS, Köhnke T, et al. Blockade of the PD-1/PD-L1 axis augments lysis of AML cells by the CD33/CD3 BiTE antibody construct AMG 330: Reversing a T-cell-induced immune escape mechanism. Leukemia. 2016;30:484-91.

89. Krönig H, Kremmler L, Haller B, Englert C, Peschel C, Andreesen R, et al. Interferon-induced programmed death-ligand 1 (PD-L1/B7-H1) expression increases on human acute myeloid leukemia blast cells during treatment. Eur J Haematol. 2014;92:195-203. 
90. Ravandi F, Walter RB, Subklewe M, Buecklein V, Jongen-Lavrencic M, Paschka P, et al. Updated results from phase I dose-escalation study of AMG 330, a bispecific T-cell engager molecule, in patients with relapsed/refractory acute myeloid leukemia (R/R AML). J Clin Oncol. 2020;38:7508.

91. Harrington KH, Gudgeon CJ, Laszlo GS, Newhall KJ, Sinclair AM, Frankel SR, et al. The broad Anti-AML activity of the CD33/CD3 BiTE antibody construct, AMG 330, is impacted by disease stage and risk. PLoS One. 2015;10:e0135945.

92. Brauchle B, Goldstein RL, Karbowski CM, Henn A, Li CM, Bücklein VL, et al. Characterization of a novel FLT3 BiTE molecule for the treatment of acute myeloid leukemia. Mol Cancer Ther. 2020;19:1875-88.

93. Uy GL, Rettig MP, Vey N, Godwin J, Foster MC, Rizzieri DA, et al. Phase 1 cohort expansion of flotetuzumab, a $\mathrm{CD} 123 \times \mathrm{CD} 3$ bispecific dart ${ }^{\circledR}$ protein in patients with relapsed/refractory acute myeloid leukemia (AML). Blood. 2018;132:764.

94. Uy GL, Aldoss I, Foster MC, Sayre PH, Wieduwilt MJ, Advani AS, et al. Flotetuzumab as salvage immunotherapy for refractory acute myeloid leukemia. Blood. 2021;137:751-62.

95. Kenderian SS, Ruella M, Shestova O, Klichinsky M, Kim MY, Porter DL, et al. Identification of PD1 and TIM3 as checkpoints that limit chimeric antigen receptor T cell efficacy in leukemia. Blood. 2015;126:852.

96. Rotiroti MC, Buracchi C, Arcangeli S, Galimberti S, Valsecchi MG, Perriello VM, et al. Targeting CD33 in chemoresistant AML patient-derived xenografts by CAR-CIK cells modified with an improved SB transposon system. Mol Ther. 2020;28:1974-86.

97. Chong EA, Melenhorst JJ, Lacey SF, Ambrose DE, Gonzalez V, Levine BL, et al. PD-1 blockade modulates chimeric antigen receptor (CAR)-modified T cells: Refueling the CAR. Blood 2017;129:1039-41.

98. Maude SL, Hucks GE, Seif AE, Talekar MK, Teachey DT, Baniewicz D, et al. The effect of pembrolizumab in combination with CD19-targeted chimeric antigen receptor (CAR) T cells in relapsed acute lymphoblastic leukemia (ALL). J Clin Oncol. 2017;35:103.

99. Stadtmauer EA, Fraietta JA, Davis MM, Cohen AD, Weber KL, Lancaster E et al. CRISPR-engineered T cells in patients with refractory cancer. Science. 2020;367: eaba7365

100. You L, Han Q, Zhu L, Zhu Y, Bao C, Yang C, et al. Decitabine-mediated epigenetic reprograming enhances anti-leukemia efficacy of CD123-targeted chimeric antigen receptor T-cells. Front Immunol. 2020;11:1787.

101. Wang Y, Tong C, Dai H, Wu Z, Han X, Guo Y, et al. Low-dose decitabine priming endows CAR $T$ cells with enhanced and persistent antitumour potential via epigenetic reprogramming. Nat Commun. 2021;12:1-18.

102. Yadav RK, Ali A, Kumar S, Sharma A, Baghchi B, Singh P et al. CAR T cell therapy: newer approaches to counter resistance and cost. Heliyon. 2020;6:e03779.

103. Hosseinkhani N, Derakhshani A, Kooshkaki O, Shadbad MA, Hajiasgharzadeh K, Baghbanzadeh $\mathrm{A}$, et al. Immune checkpoints and car-t cells: the pioneers in future cancer therapies? Int J Mol Sci 2020;21:1-28.

104. Daver NG, Garcia-Manero G, Konopleva MY, Alfayez M, Pemmaraju N, Kadia TM et al. Azacitidine (AZA) with Nivolumab (Nivo), and AZA with Nivo + Ipilimumab (Ipi) in relapsed/refractory acute myeloid leukemia: a non-randomized, prospective, phase 2 study. Blood. 2019;134:830.

105. Raneros $A B$, Minguela $A$, Rodriguez RM, Colado $E$, Bernal $T$, Anguita $E$. et al. Correction to 'Increasing TIMP3 expression by hypomethylating agents diminishes soluble MICA, MICB and ULBP2 shedding in acute myeloid leukemia, facilitating NK cell-mediated immune recognition' [Oncotarget. 2017; 8:3195976]. Oncotarget. 2018;9:32881-32881.

106. Mardiana S, John LB, Henderson MA, Slaney $C Y$, Von Scheidt $B$, Giuffrida L, et al. A multifunctional role for adjuvant anti-4-1BB therapy in augmenting antitumor response by chimeric antigen receptor T cells. Cancer Res. 2017;77:1296-309.

107. Chmielewski M, Hombach AA, Abken H. Of CARs and TRUCKs: Chimeric antigen receptor (CAR) T cells engineered with an inducible cytokine to modulate the tumor stroma. Immunol Rev. 2014;257:83-90.

108. Adachi K, Kano Y, Nagai T, Okuyama N, Sakoda Y, Tamada KIL-7. and CCL19 expression in CAR-T cells improves immune cell infiltration and CAR-T cell survival in the tumor. Nat Biotechnol. 2018;36:346-51.

109. Sabatino M, Hu J, Sommariva M, Gautam S, Fellowes V, Hocker JD, et al. Generation of clinical-grade CD19-specific CAR-modified CD81 memory stem cells for the treatment of human B-cell malignancies. Blood. 2016;128:519-28.

110. Alizadeh D, Wong RA, Yang X, Wang D, Pecoraro JR, Kuo CF, et al. IL15 enhances CAR-T cell antitumor activity by reducing mTORC1 activity and preserving their stem cell memory phenotype. Cancer. Immunol Res. 2019;7:759-72.

111. Arcangeli S, Falcone L, Camisa B, De Girardi F, Biondi M, Giglio F et al. NextGeneration Manufacturing Protocols Enriching TSCM CAR T Cells Can Overcome Disease-Specific T Cell Defects in Cancer Patients. Front Immunol. 2020;11:1217.

112. Ataca Atilla $\mathrm{P}, \mathrm{McKenna} \mathrm{MK}$, Tashiro $\mathrm{H}$, Srinivasan $\mathrm{M}, \mathrm{Mo} F$, Watanabe $\mathrm{N}$ et al. Modulating tnfa activity allows transgenic il15-expressing cll-1 car t cells to safely eliminate acute myeloid leukemia. J Immunother Cancer. 2020;8: e001229.
113. Borriello A, Caldarelli I, Bencivenga D, Stampone E, Perrotta S, Oliva A, et al. Tyrosine kinase inhibitors and mesenchymal stromal cells: Effects on selfrenewal, commitment and functions. Oncotarget. 2017;8:5540-65.

114. Wang LCS, Lo A, Scholler J, Sun J, Majumdar RS, Kapoor V, et al. Targeting fibroblast activation protein in tumor stroma with chimeric antigen receptor T cells can inhibit tumor growth and augment host immunity without severe toxicity. Cancer Immunol Res. 2014;2:154-66.

115. Raffaghello L, Vacca A, Pistoia V, Ribatti D. Cancer associated fibroblasts in hematological malignancies. Oncotarget. 2015;6:2589-603.

116. Kalluri R. The biology and function of fibroblasts in cancer. Nat Rev Cancer 2016;16:582-98.

117. Le Naour J, Galluzzi L, Zitvogel L, Kroemer G, Vacchelli E Trial watch: IDO inhibitors in cancer therapy. Oncoimmunology. 2020;9:1777625.

118. Finetti F, Travelli C, Ercoli J, Colombo G, Buoso E, Trabalzini L. Prostaglandin E2 and cancer: Insight into tumor progression and immunity. Biol (Basel). 2020;9:1-26.

119. Ciardiello D, Elez E, Tabernero J, Seoane J. Clinical development of therapies targeting TGF $\beta$ : current knowledge and future perspectives. Ann Oncol. 2020;31:1336-49.

120. Musso A, Catellani $S$, Canevali $P$, Tavella $S$, Venè $R$, Boero $S$, et al. Aminobisphosphonates prevent the inhibitory effects exerted by lymph node stromal cells on anti-tumor Vd 2 T lymphocytes in non-hodgkin lymphomas. Haematologica. 2014;99:131-9.

121. Uy GL, Rettig MP, Motabi IH, McFarland K, Trinkaus KM, Hladnik LM, et al. A phase $1 / 2$ study of chemosensitization with the CXCR4 antagonist plerixafor in relapsed or refractory acute myeloid leukemia. Blood. 2012;119:3917-24.

122. Farge T, Saland E, Toni F De, Aroua N, Hosseini M, Perry R, et al. Chemotherapy-Resistant Human Acute Myeloid Leukemia Cells Are Not Enriched for Leukemic Stem Cells but Require Oxidative Metabolism. Cancer Discov. 2017;7:716-35.

123. Holubarsch CJF, Rohrbach $M$, Karrasch $M$, Boehm E, Polonski L, Ponikowski $P$, et al. A double-blind randomized multicentre clinical trial to evaluate the efficacy and safety of two doses of etomoxir in comparison with placebo in patients with moderate congestive heart failure: the ERGO (etomoxir for the recovery of glucose oxidation) stud. Clin Sci. 2007;113:205-12.

124. Tcheng M, Samudio I, Lee EA, Minden MD, Spagnuolo PA. The mitochondria target drug avocatin $B$ synergizes with induction chemotherapeutics to induce leukemia cell death. Leuk Lymphoma. 2017;58:986-8.

125. Beavis PA, Henderson MA, Giuffrida L, Mills JK, Sek K, Cross RS et al. Targeting the adenosine $2 \mathrm{~A}$ receptor enhances chimeric antigen receptor $T$ cell efficacy. J Clin Invest. 2017;127:929-41.

126. Giuffrida L, Sek K, Henderson MA, Lai J, Chen AXY, Meyran D, et al. CRISPR/Cas9 mediated deletion of the adenosine A2A receptor enhances CAR T cell efficacy. Nat Commun. 2021;12:3236

127. Naik J, Themeli M, de Jong-Korlaar R, Ruiter RWJ, Poddighe PJ, Yuan $H$, et al. CD38 as a therapeutic target for adult acute myeloid leukemia and T-cell acute lymphoblastic leukemia. Haematologica 2019;104:e100-3.

128. Mistry JJ, Moore JA, Kumar P, Marlein CR, Hellmich C, Pillinger G, et al. Daratumumab inhibits acute myeloid leukemia metabolic capacity by blocking mitochondrial transfer from mesenchymal stromal cells. Haematologica 2021;106:589-92.

129. Farber M, Arnold L, Chen Y, Möllmann M, Duehrsen U, Hanoun M. Inhibition of CD38 Shows Anti-Leukemic Activity in Acute Myeloid Leukemia. Blood. 2018;132:1456.

130. Marlein CR, Zaitseva L, Piddock RE, Raso-Barnett L, Scott MA, Ingham CJ, et al. PGC-1a driven mitochondrial biogenesis in stromal cells underpins mitochondrial trafficking to leukemic blasts. Leukemia. 2018;32:2073-7.

131. Sinclair KA, Yerkovich ST, Hopkins PMA, Chambers DC. Characterization of intercellular communication and mitochondrial donation by mesenchymal stromal cells derived from the human lung. Stem Cell Res Ther. 2016;7:1-10.

132. Gratton JP, Lin MI, Yu J, Weiss ED, Jiang ZL, Fairchild TA, et al. Selective inhibition of tumor microvascular permeability by cavtratin blocks tumor progression in mice. Cancer Cell. 2003;4:31-39.

133. Ma C, Witkowski MT, Harris J, Dolgalev I, Sreeram S, Qian W et al. Leukemia-on-achip: Dissecting the chemoresistance mechanisms in B cell acute lymphoblastic leukemia bone marrow niche. Sci Adv. 2020;6:eaba5536.

134. Baryawno N, Przybylski D, Kowalczyk MS, Kfoury Y, Severe N, Gustafsson K, et al. A cellular taxonomy of the bone marrow stroma in homeostasis and leukemia. Cell. 2019;177:1915-32.e16.

135. Kobayashi K, Sakamoto J, Kito T, Yamamura Y, Koshikawa T, Fujita M, et al. Lewis blood group-related antigen expression in normal gastric epithelium, intestinal metaplasia, gastric adenoma, and gastric carcinoma. Am J Gastroenterol. 1993;88:919-24. 


\section{ACKNOWLEDGEMENTS}

This work was supported by AIRC 2015-17248 to M.S., Ministero della Salute-Ricerca Finalizzata-Giovani Ricercatori GR-2016-02363491 to S.T., AIRC $5 \times 1000$ 2018-21147 to A.B., PRIN 2017-NAZ-0412 to A.B, the Ministero della Salute CAR T project of the "Rete Oncologica" and AIRC/Cancer Research UK (CRUK)/Fundación Científica de la Asociación Española Contra el Cáncer (FC AECC) 22791 to AB. The authors also thank the parent committees Comitato Maria Letizia Verga, Quelli che con LUCA Onlus, Associazione Amici di Duccio and Comitato Stefano Verri, for their generous and constant support.

\section{AUTHOR CONTRIBUTIONS}

ST and AP wrote the paper and prepared the figures; GD and MS wrote and reviewed the paper; $A B$ edited the paper.

\section{COMPETING INTERESTS}

The authors declare no competing interests.

\section{ADDITIONAL INFORMATION}

Correspondence and requests for materials should be addressed to A.B.
Reprints and permission information is available at http://www.nature.com/ reprints

Publisher's note Springer Nature remains neutral with regard to jurisdictional claims in published maps and institutional affiliations.

\section{(c) (i)}

Open Access This article is licensed under a Creative Commons Attribution 4.0 International License, which permits use, sharing, adaptation, distribution and reproduction in any medium or format, as long as you give appropriate credit to the original author(s) and the source, provide a link to the Creative Commons license, and indicate if changes were made. The images or other third party material in this article are included in the article's Creative Commons license, unless indicated otherwise in a credit line to the material. If material is not included in the article's Creative Commons license and your intended use is not permitted by statutory regulation or exceeds the permitted use, you will need to obtain permission directly from the copyright holder. To view a copy of this license, visit http://creativecommons. org/licenses/by/4.0/.

(c) The Author(s) 2021 